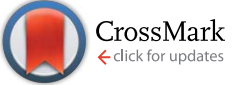

Cite this: RSC Adv., 2017, 7, 10891

\title{
Enhancement of $A s(v)$ adsorption from aqueous solution by a magnetic chitosan/biochar composite
}

Received 25th November 2016 Accepted 6th February 2017

DOI: 10.1039/c6ra27341f

rsc.li/rsc-advances

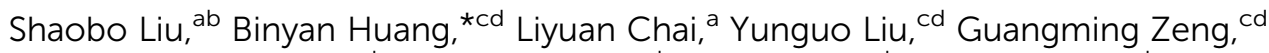 \\ Xin Wang, ${ }^{e}$ Wei Zeng, ${ }^{\text {cd }}$ Meirong Shang, ${ }^{\text {cd }}$ Jiaqin Deng ${ }^{\text {cd }}$ and Zan Zhou ${ }^{c d}$
}

In this study, a magnetic chitosan/biochar composite (MCB) was prepared successfully, and characterized by SEM, TEM, VSM, XRD, FTIR, XPS, and zeta-potential to obtain its physical and chemical properties. The influence of different sorption parameters such as $\mathrm{pH}$, contact time, initial $\mathrm{As}(\mathrm{V})$ concentration, and temperature on As(v) removal were studied thoroughly in order to optimize the reaction conditions. The results showed that the MCB adsorbed more As(v) (11.961 $\mathrm{mg} \mathrm{g}^{-1}$ ) than pristine biochar $\left(3.681 \mathrm{mg} \mathrm{g}^{-1}\right.$ ). In addition, the adsorption behavior could be well described by a pseudo-second-order and Langmuir model. Thermodynamic parameters revealed that the sorption reaction was a spontaneous and

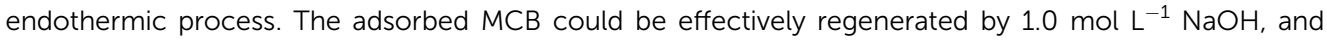
the adsorption capacity decreased from 11.823 to $8.078 \mathrm{mg} \mathrm{g}^{-1}$ in five cycles. In conclusion, MCB could be used as an efficient adsorbent for environment purification and conveniently separated from aqueous solution after adsorption.

\section{Introduction}

Arsenic (As) is known as one of the most toxic chemical elements at very low concentrations, contamination of natural waters by inorganic arsenic (As) has dire consequences for public health all around the world because of its potential synonymy with toxicity. ${ }^{1,2}$ The release of As can occur naturally from geothermal and groundwater, ${ }^{3}$ or by anthropogenic activities, such as mining, ${ }^{4}$ feed additives ${ }^{5}$ and wood preservation. ${ }^{6}$ High As concentrations in groundwater have been found in Argentina, Bangladesh, Chile, China, Hungary, Mexico, West Bengal (India), and Vietnam. ${ }^{7,8}$ Ingestion of arsenic contaminated drinking water can result in both skin cancer and internal cancers, particularly of the lung and urinary tract. ${ }^{9}$ The predominant form of inorganic arsenic commonly found in natural waters were oxyanions of trivalent arsenite $\left(\mathrm{AsO}_{3}{ }^{3-}\right.$, $\mathrm{As}(\mathrm{III}))$ and pentavalent arsenate $\left(\mathrm{AsO}_{4}{ }^{3-}, \mathrm{As}(\mathrm{v})\right) .{ }^{10}$ Although, $\mathrm{As}(\mathrm{v})$ tends to be less toxic compared with As(III), it is thermodynamically more stable due to which it predominates under

${ }^{a}$ School of Metallurgy and Environment, Central South University, Changsha 410083, P. R. China

${ }^{b}$ School of Architecture and Art, Central South University, Changsha 410083, P. R. China

'College of Environmental Science and Engineering, Hunan University, Changsha 410082, P. R. China. E-mail: hby617125216@163.com; Fax: +86 731 88822829; Tel: +8673188649208

${ }^{d}$ Key Laboratory of Environmental Biology and Pollution Control, Hunan University, Ministry of Education, Changsha 410082, P. R. China

${ }^{e}$ College of Resources and Environmental Science, Hunan Normal University, Changsha 410006, P. R. China normal conditions. Therefore, removal of $\mathrm{As}(\mathrm{v})$ is potentially important as $\mathrm{As}$ (III) irrespective of toxicity, ${ }^{11}$ and removing As effectively from water supplies is essential to protecting environmental and human health.

Several methods have been developed to remove arsenic from water, such as, membrane technologies, ${ }^{12}$ ion exchange, ${ }^{13}$ oxidation/reduction, ${ }^{14}$ oxidation-coagulation ${ }^{15}$ and adsorption. ${ }^{16}$ Among these techniques, the adsorption process is considered one of most promising techniques because it is economical, effective, and no sludge disposal. Various types of sorbents have been developed and applied for water treatment during the past few decades. ${ }^{17}$

Compared with conventional carbonaceous materials such as commercial activated carbon, the primary advantages of biochar are its low cost and a wealth of sources of biomass. ${ }^{18,19}$ However, pristine biochar prepared from biomass feedstock without any treatment have relatively low heavy metal sorption capacity, and their sorption for aqueous As, which is in anionic forms of either arsenate (As(v)) or arsenite ( $\mathrm{As}(\mathrm{III}))$, is relatively low due to most of biochar are predominantly net negatively charged on the surface. ${ }^{20}$ Several methods have thus been developed to modify biochar to enhance its sorption for As. Chitosan is another sorbent that has been widely used to remove water pollutants because it is abundant, renewable, biodegradable and non-toxic in nature. ${ }^{21}$ It is characterized by both large sorption capacity owing to the position of $-\mathrm{OH}$ and $-\mathrm{NH}_{2}$ groups and high hydrophilicity with a large number of hydroxyl groups of glucose units and the presence of a large number of functional groups (acetamido, primary amino and/or hydroxyl groups). ${ }^{22,23}$ Using chitosan modified biochar could 
show good performance to improve the adsorption ability of $\operatorname{As}(\mathrm{v})$.

Although the chitosan/biochar composite exhibited good sorption ability, it is cannot be separated easily from aqueous solution. Magnetic fluids have the capability to treat large number of wastewater within a short time and can be conveniently separated from wastewater. What's more, the magnetic fluids can increase the number of adsorption sites and enhance the adsorption capacity for arsenic. ${ }^{24}$ Thus, coating chitosan with magnetic fluids can expand function of the chitosan, and the method has been reported that it can improve the surface area for adsorption. ${ }^{25}$ Therefore, the magnetic chitosan modified with biochar could not only enhance the sorption ability but also be magnetically collected after adsorption.

The objective of this paper focused on enhancing the $\operatorname{As}(\mathrm{v})$ removal ability by the magnetic chitosan/biochar composite (MCB). The samples were characterized by Fourier transform infrared (FTIR), scanning electron microscope (SEM), transmission electron microscopy (TEM), vibrating sample magnetometry (VSM), X-ray photoelectron spectroscopy (XPS), X-ray diffraction (XRD) and zeta potential. In addition, kinetic, isothermal and thermodynamic analysis have been conducted in this paper. The desorption/regeneration properties of MCB were investigated to determine the reusability of adsorbent and evaluate the economic feasibility. The As(v) removal mechanisms was investigated by XPS analysis.

\section{Materials and methods}

\subsection{Materials}

All chemicals used in this study were purchased at analytical reagent grade and without any further purification. Rice straw (RS), the source of biomass, was obtained from Zhuzhou, Hunan province, China. Chitosan (95\% acetylation degree) was provided by Hefei Bomei Biotechnology Co., Ltd. Glutaraldehyde was supplied by Sonopharm Chemical Reagent Co., Ltd. The disodium hydrogen arsenate heptahydrate $\left(\mathrm{Na}_{2} \mathrm{HAsO}_{4}{ }^{-}\right.$ $\cdot 7 \mathrm{H}_{2} \mathrm{O}$ ) was purchased from Sigma Aldrich with a purity higher than $98 \%$. The stock solution of $100 \mathrm{mg} \mathrm{L}^{-1} \mathrm{As}(\mathrm{v})$ was prepared by dissolving $0.4165 \mathrm{~g} \mathrm{Na}{ }_{2} \mathrm{HAsO}_{4} \cdot 7 \mathrm{H}_{2} \mathrm{O}$ in $1 \mathrm{~L}$ ultra-water, and the required concentrations were obtained by diluting the stock solution with deionized water.

\subsection{Preparation of adsorbent}

The biomass was air-dried for two days, and subsequently ovendried at $60{ }^{\circ} \mathrm{C}$ for $48 \mathrm{~h}$. By pyrolysis of the biomass in a tube furnace at $450{ }^{\circ} \mathrm{C}$ with a heating rate of $5{ }^{\circ} \mathrm{C} \mathrm{min}{ }^{-1}$ under $\mathrm{N}_{2}$ atmosphere for $2 \mathrm{~h}$, the obtained biochar was ground and sieved through 150-mesh screen.

Magnetic fluid was prepared by co-precipitation method according to the former study. ${ }^{26}$ Briefly, $\mathrm{Fe}^{2+}$ and $\mathrm{Fe}^{3+}$ (molar ratio $2: 3$ ) solution were added into the beaker with stirring at $55^{\circ} \mathrm{C}$ and then dropwise $\mathrm{NaOH}$ solution with constant stirring for $10 \mathrm{~min}$ until $\mathrm{pH}$ reached 9.0. After adjusting the temperature of the reaction vessels to $65^{\circ} \mathrm{C}, 0.8 \mathrm{~mL}$ Tween 80 was added into the mixture with stirring for another $30 \mathrm{~min}$, and adjusted the
$\mathrm{pH}$ value to 7.0. Then, the product was washed with Milli-Q water three times and was dispersed in ultrasonic device for $40 \mathrm{~min}$. Finally, the solution was diluted to obtain magnetic fluid $\left(40 \mathrm{~g} \mathrm{~L}^{-1}\right)$.

The magnetic chitosan modified with biochar (MCB) was synthesized as follow: $2.0 \mathrm{~g}$ chitosan was dissolved in $100 \mathrm{~mL}$ $2 \%$ acetic solution with stirring. Next, $10 \mathrm{~mL}$ magnetic fluid was added dropwise into the solution with constantly stirring for $30 \mathrm{~min}$ in a water bath at $50{ }^{\circ} \mathrm{C}$. Then $1.0 \mathrm{~g}$ biochar was added with constantly stirring for another $60 \mathrm{~min}$. After that, $4 \mathrm{~mL}$ glutaraldehyde was injected into the reaction system to form the gel and the $\mathrm{pH}$ of the reaction system was adjusted to 8.0-10.0. Finally, the mixture was kept in a water bath for a further $1 \mathrm{~h}$. The precipitate were washed until the $\mathrm{pH}$ was about 7 , and was dried at $60{ }^{\circ} \mathrm{C}$, and sieved. The composite of chitosan modified with biochar (CB) was synthesized via the preparation of $\mathrm{MCB}$ without adding magnetic fluid.

\subsection{Characterization and investigation of $\mathrm{As}(\mathrm{v})$ sorption by MCB}

The morphologies of B and MCB were characterized by scanning electron microscopy (SEM) (JEOL JSM-6700. Japan) and transmission electron microscopy (TEM, Tecnai G2 F20, USA). The magnetization measurement of magnetic fluid and MCB were performed by vibrating sample magnetometer (VSM) (MPMS XL-7. America). The X-ray diffraction (XRD) patterns of $\mathrm{CB}$ and MCB were obtained by an X-ray diffractometer (Rigaku $\mathrm{D} / \mathrm{max}-2500$, Japan) with $\mathrm{CuK} \alpha$ radiation. The Fourier transform infrared spectroscopy (FTIR) were measured on a spectrophotometer (Nicolet, Magna 550 spectrometer). Surface chemical composition of B, MCB were confirmed by an ESCALAB $250 \mathrm{Xi}$ X-ray Photoelectron Spectrometer (XPS) (Thermo Fisher, USA). The iron ions concentrations were determined by a flame atomic absorption spectrometry (PerkinElmer AA700, USA). Zeta-potential of MCB was obtained from an Electroacoustic Spectrometer (ZEN3600 Zetasizer UK) under solution $\mathrm{pH}$ varying from 3.0 to 11.0 .

\subsection{Sorption experiments}

All batch experiments were carried out with $20 \mathrm{mg}$ adsorbent in

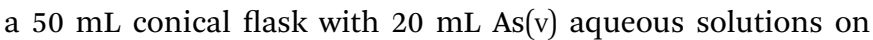
a rotary shaker at $150 \mathrm{rpm}$ for specific time. The $\mathrm{pH}$ of initial solutions was adjusted by $\mathrm{HCl}$ or $\mathrm{NaOH}$. After being mixed for $24 \mathrm{~h}$, the mixture was drawn and separated immediately by an aid of external magnet, and the residual concentrations was determined by atomic fluorescence spectroscopy (AFS-9700, China). The adsorption amount removed by the adsorbent, $q_{\mathrm{e}}$ $\left(\mathrm{mg} \mathrm{g}^{-1}\right)$ was calculated as follows:

$$
q_{\mathrm{e}}=\frac{C_{0}-C_{\mathrm{e}}}{m} \times V
$$

where $C_{0}\left(\mathrm{mg} \mathrm{L}^{-1}\right)$ and $C_{\mathrm{e}}\left(\mathrm{mg} \mathrm{L}^{-1}\right)$ are the initial and equilibrium concentration of $\mathrm{As}(\mathrm{v}), V(\mathrm{~L})$ is stand for the volume of solution, and $m(\mathrm{~g})$ is the weight of adsorbent.

The effect of $\mathrm{pH}$ on sorption experiment by three different materials ( $\mathrm{B}, \mathrm{CB}, \mathrm{MCB})$ were carried out by varying $\mathrm{pH}$ value 
between 3.0 and 11.0 with $15 \mathrm{mg} \mathrm{L}^{-1} \mathrm{As}(\mathrm{v})$ for $24 \mathrm{~h}$, and the mixtures were shaken with a speed of $150 \mathrm{rpm}$ for $24 \mathrm{~h}$ at $25^{\circ} \mathrm{C}$.

The kinetic experiments were performed with different time intervals $(0,5,15,30,60,90,120,180,240,360,480,600,1020$, $1440 \mathrm{~min}$ ) at $\mathrm{pH} 5.0$, and the other parameters kept constant.

The isotherm experiments were conducted by varying initial concentrations from $0.2 \mathrm{mg} \mathrm{L}^{-1}$ to $50 \mathrm{mg} \mathrm{L}^{-1}$ at three different temperatures $\left(25,35,45^{\circ} \mathrm{C}\right)$, and adjusted $\mathrm{pH}$ value to 5.0.

All the experimental treatments were performed in three samples and the average values were reported. The relative errors of the data were generally within $5 \%$.

\subsection{Desorption experiment}

The detailed desorption experiment was implemented as follows: the adsorbent which used to adsorb As(v) was added into $20 \mathrm{~mL} 1.0 \mathrm{~mol} \mathrm{~L}^{-1} \mathrm{NaOH}$ solution with a shaking speed $150 \mathrm{rpm}$ at $25{ }^{\circ} \mathrm{C}$ for $24 \mathrm{~h}$. The adsorbent was subsequently washed to neutral and collected for recycling.

The resulted experimental data was obtained from the average of three measured value. The relative errors of the dada were within $5 \%$.

\section{Result and discussion}

\subsection{Characterization}

3.1.1 SEM and TEM. The surface property is important for biochar reactivity and the magnification images of B and MCB are shown in Fig. 1. As shown in Fig. 1a, it could be obviously found that the surface of B was smooth and irregular. As can be seen in Fig. 1b, the prepared sample has a layered and porous structure due to the intrinsic nature of the biochar. It was noted in Fig. 1c that the MCB had an irregular surface with different shapes and many flakes, and the surface became much rougher and more heterogeneous, which might be attributed to the enhancement of superficial area. Compared with B in Fig. 1b, the surfaces of MCB in Fig. 1d had noticeable metal luster, indicating that the magnetic fluid had been assembled on the surface of MCB.

3.1.2 VSM. Fig. 2a show the VSM of magnetic fluid and $\mathrm{MCB}$, and the typical hysteresis loop (S-like curve) were presented, which indicated super-magnetization of the composites. $^{27}$ The saturation magnetization is found to be 67.0 and $16.67 \mathrm{emu} \mathrm{g}^{-1}$ for magnetic fluid and MCB, respectively. This decline can be attributed to the relatively low amount of magnetic fluid, the existence of biochar and the surface modification by chitosan. ${ }^{28}$ Although the saturation magnetization values of MCB are lower than that of bare magnetic fluid, the magnetic property of MCB remained high enough to meet the needs for magnetic separation. The inset in Fig. 2a demonstrated that MCB had a favorable separation characteristic and the feasibility of MCB for sequestrating As(v) from aqueous solution.

3.1.3 XRD. The XRD pattern of CB and MCB is illustrated in Fig. 2b. As can be seen, an amorphous structure was displayed in $\mathrm{CB}$ XRD pattern. However, there were six intense characteristic peaks in $\mathrm{MCB}$ at $2 \theta=30.1^{\circ}, 35.5^{\circ}, 43.3^{\circ}, 53.4^{\circ}, 57.2^{\circ}$ and $63.1^{\circ}$, which was corresponded to the primary diffraction of the (220), (311), (222), (400), (422) and (440) facets of the cubic spinel crystal planes of $\mathrm{Fe}_{3} \mathrm{O}_{4}$ (JCPDS card no. 16-0629). ${ }^{29}$ The result indicated that magnetic fluid was coated with the composite successfully, and the final composite might be separated conveniently from aqueous solution by an external magnet field to avoid secondary pollution after As(v) adsorption.

3.1.4 FTIR. Fig. 2c shows the FTIR spectrum of B, CB and MCB. The stretching bands at about $1095 \mathrm{~cm}^{-1}$ (C-O), 1417 $\mathrm{cm}^{-1}\left(-\mathrm{CH}_{2}\right), 1576 \mathrm{~cm}^{-1}(\mathrm{C}=\mathrm{O})$ and $3371 \mathrm{~cm}^{-1}(-\mathrm{OH})$ were observed from RS biochar. ${ }^{30}$ Similarly, in the FTIR spectra of CB, the same functional groups above mentioned were found around the corresponding wavenumber. However, the peak at
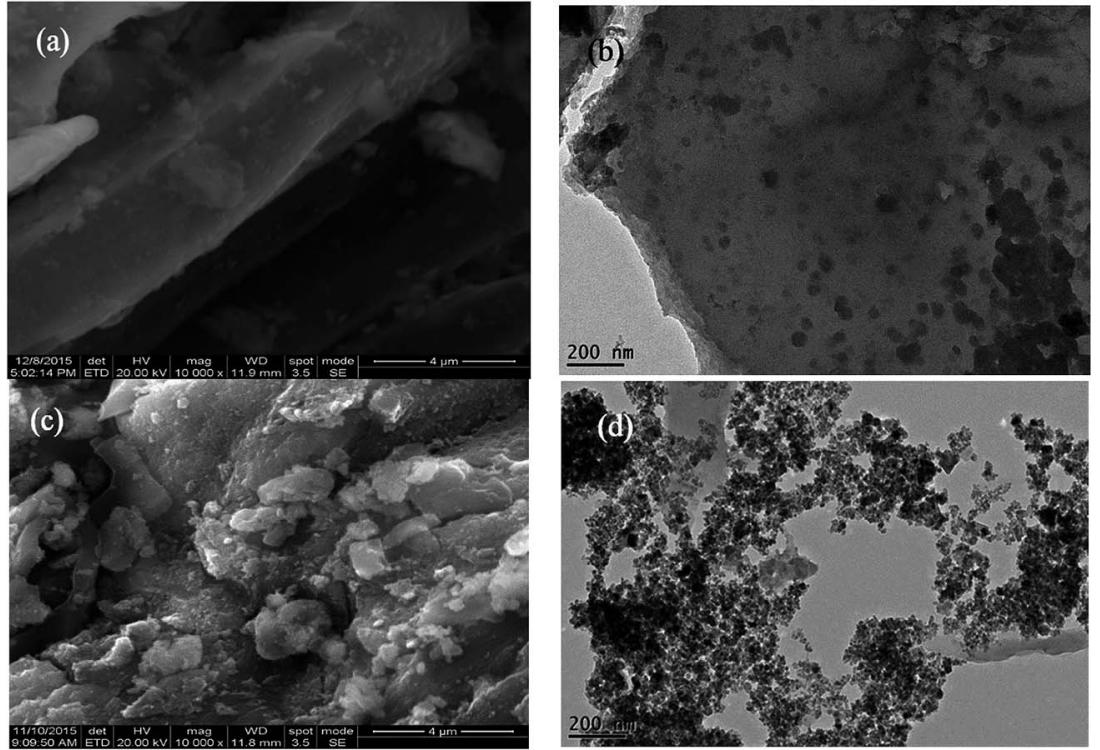

Fig. 1 The SEM images of (a) B, (c) MCB; the TEM images of (b) B, (d) MCB. 

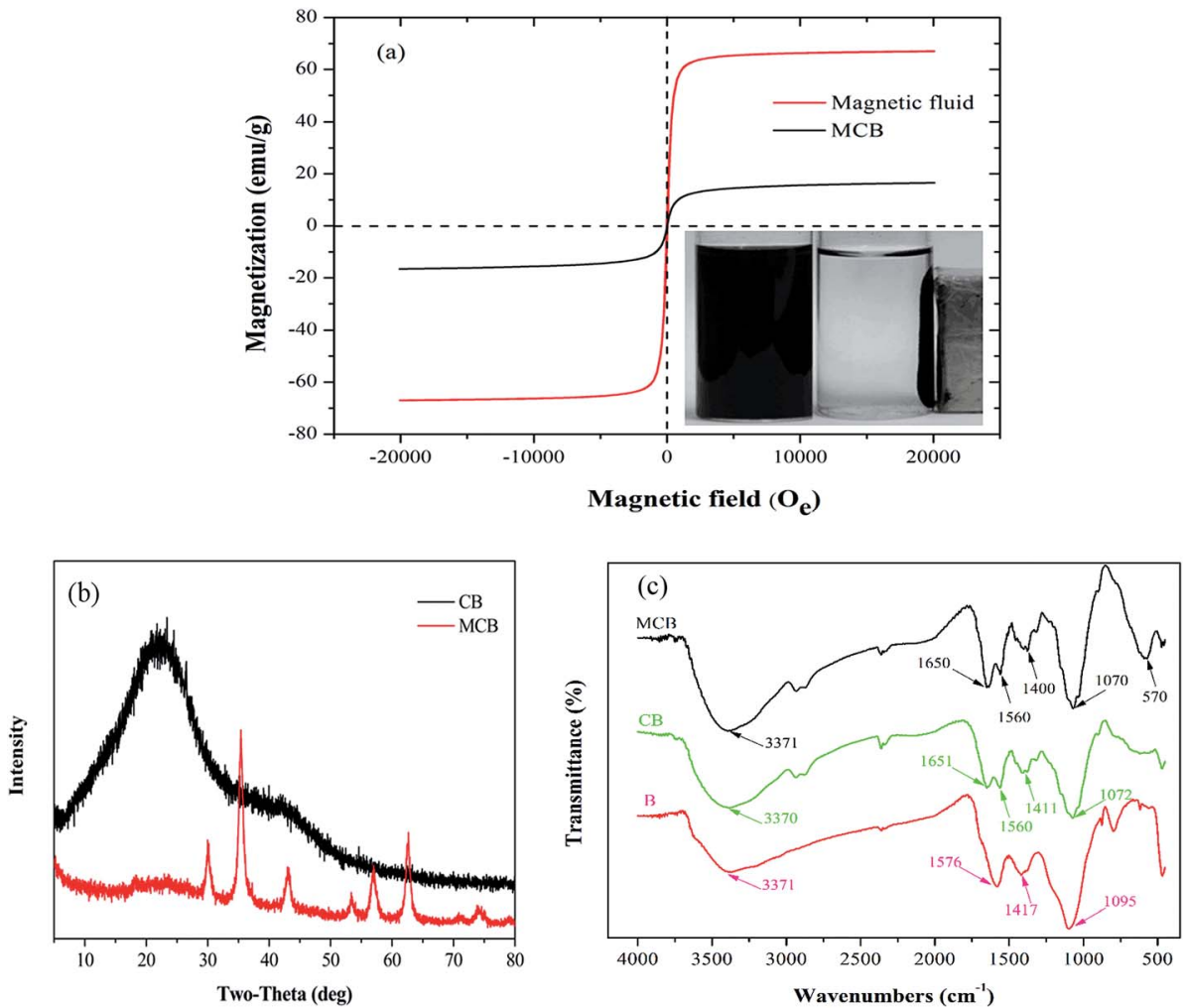

Fig. 2 (a) Magnetization curves of magnetic fluid and MCB at room temperature (the inset show the dispersion and magnetic separation of $M C B$ ). (b) XRD pattern of $C B$ and MCB. (c) FTIR spectra of $B, C B$, and MCB.

$1576 \mathrm{~cm}^{-1}$ shift to $1560 \mathrm{~cm}^{-1}$ ascribed to the amide $\mathrm{I}(\mathrm{C}=\mathrm{O}$ stretching) and a new peak was appeared at $1651 \mathrm{~cm}^{-1}$ ascribed to amide II ( $\mathrm{N}-\mathrm{H}$ blending modes), conforming that the carboxyl groups reacted with chitosan during the preparation of the composite. ${ }^{31}$ In addition, it was obviously to find the stretching vibration of Fe-O peak appeared at around $570 \mathrm{~cm}^{-1}$ in MCB spectrum, and the results confirmed that the MCB was prepared successfully.
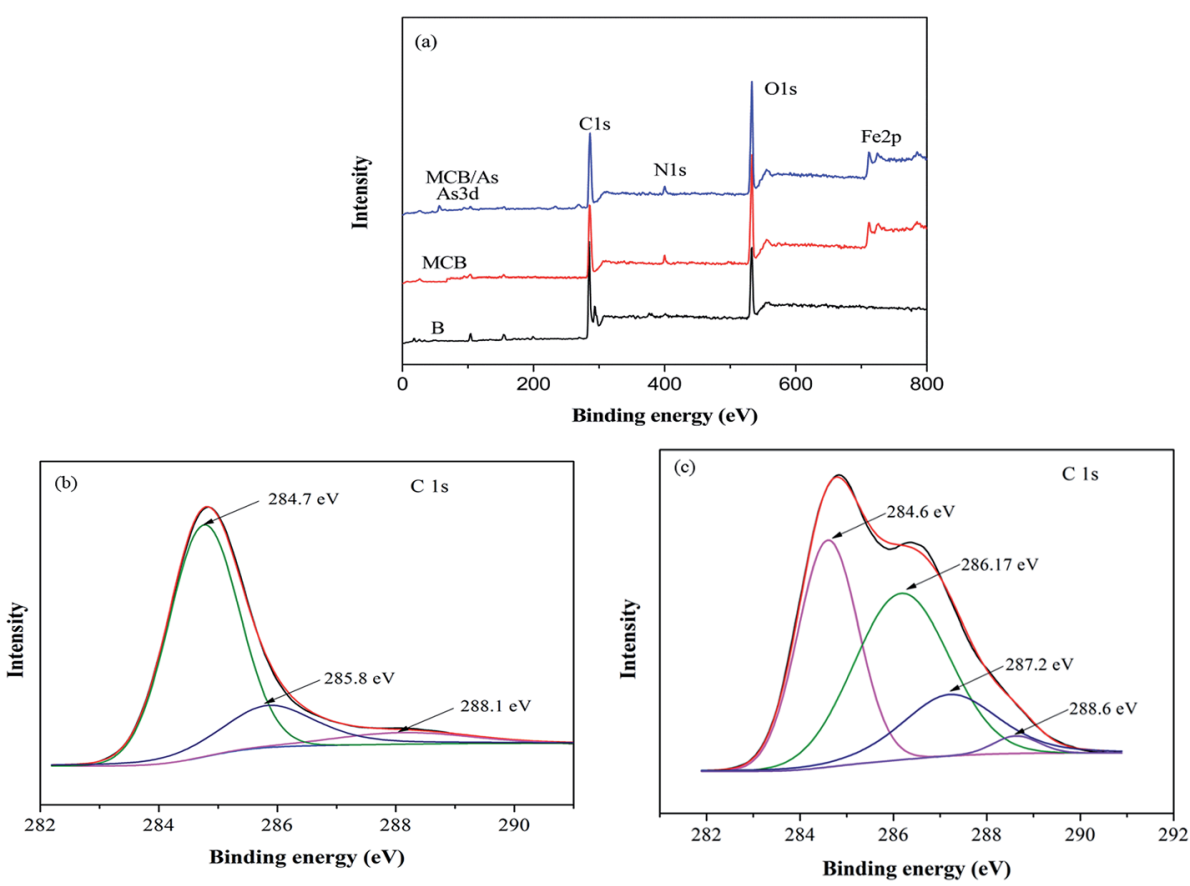

Fig. 3 (a) XPS wide-scan of B, MCB and MCB/As; C 1s XPS spectra of (b) B and (c) MCB. 
3.1.5 XPS. To further understand the chemical ingredient of B and MCB, XPS was used to study the surface composition. The full scan XPS spectrum from 0 to 800 is displayed in Fig. 3a, and the photoelectron lines at about 284.7, 400.2 and $533.2 \mathrm{eV}$ were corresponded to $\mathrm{C} 1 \mathrm{~s}, \mathrm{~N} 1 \mathrm{~s}$ and $\mathrm{O} 1 \mathrm{~s}$, respectively. Fig. $3 \mathrm{~b}$ reflected the $\mathrm{C}$ 1s XPS spectra of $\mathrm{B}$, three different peaks centered at 284.7, 285.8 and $288.1 \mathrm{eV}$ were observed, which was attributed to the carbon atoms in the forms of $\mathrm{C}-\mathrm{C}(72.1 \%), \mathrm{C}-\mathrm{O}$ $(21.2 \%)$ and $\mathrm{C}=\mathrm{O}(6.7 \%)$, respectively. ${ }^{31}$ However, the $\mathrm{C}$ 1s XPS spectrum of MCB in Fig. 3c could be well curve-fitted into four peak components around 284.6, 286.17, 287.2, and $288.6 \mathrm{eV}$, which was corresponded to $\mathrm{C}-\mathrm{C}(37.2 \%), \mathrm{C}-\mathrm{O}(42.7 \%), \mathrm{C}-\mathrm{N}$ $(18.0 \%)$, and $-\mathrm{COOH}(2.1 \%)$, respectively. The difference between biochar and MCB was probably originated from modifying magnetic chitosan with pristine biochar, and the results further confirmed that MCB was prepared successfully, which were consistent with the FTIR characterization.

\subsection{Effect of $\mathrm{pH}$ and comparison experiments}

The $\mathrm{pH}$ value controls the interaction between adsorbate and adsorbents, which is predominant for the fractional species distribution of As(v) and the surface properties of adsorbents. ${ }^{32}$ From Fig. 4a, the maximum adsorption capacity of B $(3.681 \mathrm{mg}$ $\left.\mathrm{g}^{-1}\right)$, CB (10.600 $\left.\mathrm{mg} \mathrm{g}^{-1}\right)$, and MCB (11.533 $\mathrm{mg} \mathrm{g}^{-1}$ ) reached at $\mathrm{pH}$ 4.0, 3.0 and 5.0, respectively. For MCB, the sorption capacity increased slowly over the range of 3.0-5.0, and continually decreased from 5.0 to 10.0 . This result can be interpreted as follows. In aqueous environment, there are two kind of arsenic species at $\mathrm{pH}$ range from 3.0 to $11.0, \mathrm{H}_{2} \mathrm{AsO}_{4}{ }^{-}$is predominant when $3.0<\mathrm{pH}<7.0$, while $\mathrm{HAsO}_{4}{ }^{2-}$ is the main species at $\mathrm{pH}$ 7.0-11.0. ${ }^{33}$ That is to say the main speciation of $\mathrm{As}(\mathrm{v})$ is anionic. As shown in Fig. 4b, the $\mathrm{pH}_{\mathrm{pzc}}$ (point of zeta charge) of MCB was about 5.25. Under the condition $\mathrm{pH}<\mathrm{pH}_{\mathrm{pzc}}$, the adsorbent was positively charged, which was beneficial for MCB combination with $\mathrm{As}(\mathrm{v})$. When $\mathrm{pH}>\mathrm{pH}_{\mathrm{pzc}}$, the surface of $\mathrm{MCB}$ acquired negative charges, which could go against the As(v) adsorption due to electrostatic repulsion, ${ }^{34}$ so as to the adsorption efficiency decreased significantly when the $\mathrm{pH}>5.0$. This result might confirm the hypothesis that electrostatic attraction could be one of the adsorption mechanisms. As it can be seen from Fig. 4a, As(v) adsorption onto three different materials was investigated at various $\mathrm{pH}$. It was clearly to find that $\mathrm{CB}$ had an upper hand on As(v) adsorption compared with biochar, indicating that the introduction of chitosan was beneficial for removing $\mathrm{As}(\mathrm{v})$. It might be that $-\mathrm{NH}_{2}$ and $-\mathrm{OH}$ from chitosan were protonated resulted in positively charged, which hold great promise for sequestrating $\mathrm{As}(\mathrm{v})$ due to electrostatic attraction. Thus, the sorption capacity of $\mathrm{CB}$ was much higher than biochar. Moreover, as shown in Fig. 4a, it can be also found that the sorption capacity of MCB was higher than that of $\mathrm{CB}$, which is mainly due to the high surface areas and partial positive charges of magnetic fluid that have a strong affinity for $\operatorname{As}(\mathrm{v})$ in water. ${ }^{35}$ However, the maximum adsorption of $\mathrm{As}(\mathrm{v})$ on MCB was appeared at $\mathrm{pH} 5$, and the adsorption capacity was gradually reduced as the $\mathrm{pH}$ decreased, while the $\mathrm{CB}$ has the opposite trend, this is because of the easy oxidation/dissolution
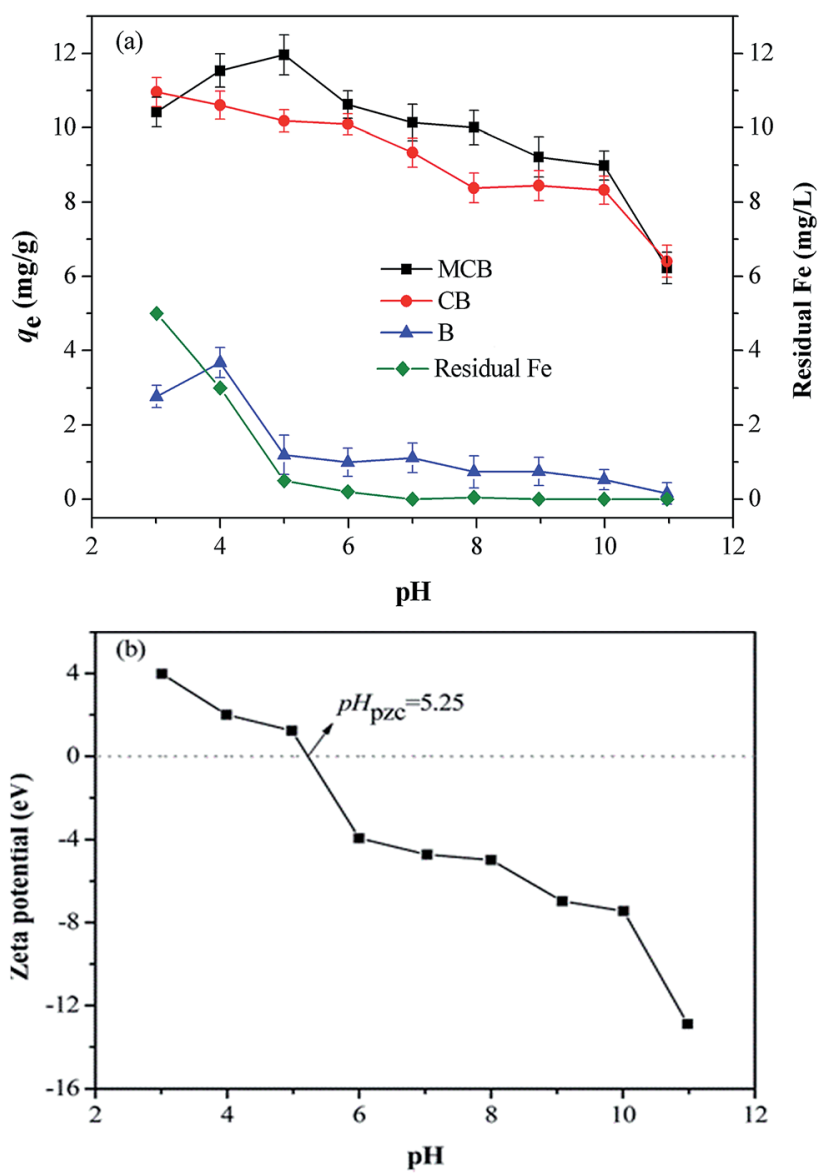

Fig. 4 (a) As(v) adsorption capacities of B, CB, MCB and residual Fe in solution with varying $\mathrm{pH}$; (b) zeta-potential of $\mathrm{MCB}$ at different solution $\mathrm{pH}$.

of iron nanoparticles, especially at high concentrations of acid solution that lead to a decrease in the sorption capacity of MCB. At the same time, we found that the stronger the acidity, the more dissolved iron ions were detected by the flame atomic absorption (Fig. 4a). When $\mathrm{pH}$ increases to 5 and above, leaching of Fe ion significantly reduces. The composite MCB is stable when the $\mathrm{pH}$ is above 5 . All in all, MCB had superiority in As(v) removal, and could be conveniently separated from after adsorption aqueous solution compared with B and CB.

\subsection{Effect of co-existing ions}

Considering the complexity of water resources, the existence of various ions, such as $\mathrm{Cl}^{-}, \mathrm{NO}_{3}{ }^{-}, \mathrm{CO}_{3}{ }^{2-}, \mathrm{SO}_{4}{ }^{2-}$ and $\mathrm{PO}_{4}{ }^{3-}$ ions might influence the uptake capacity of MCB to As(v). Therefore, the effect of co-existing ions on adsorption was conducted by batch experiments at different concentrations of $\mathrm{NaCl}, \mathrm{NaNO}_{3}$, $\mathrm{Na}_{2} \mathrm{CO}_{3}, \mathrm{Na}_{2} \mathrm{SO}_{4}$, and $\mathrm{Na}_{3} \mathrm{PO}_{4}$, and the obtained results are shown in Fig. 5. The adsorption capacity of MCB was decreased in the concentrations of various anions from 0 to $1.0 \mathrm{~mol} \mathrm{~L}^{-1}$, which might be attributed to the competition between negatively charged anions and $\mathrm{HAsO}_{4}{ }^{-}$. These anions could be easily captured by the adjacent hydroxyl or carboxyl groups that were present on the surface of MCB, which might change the surface 


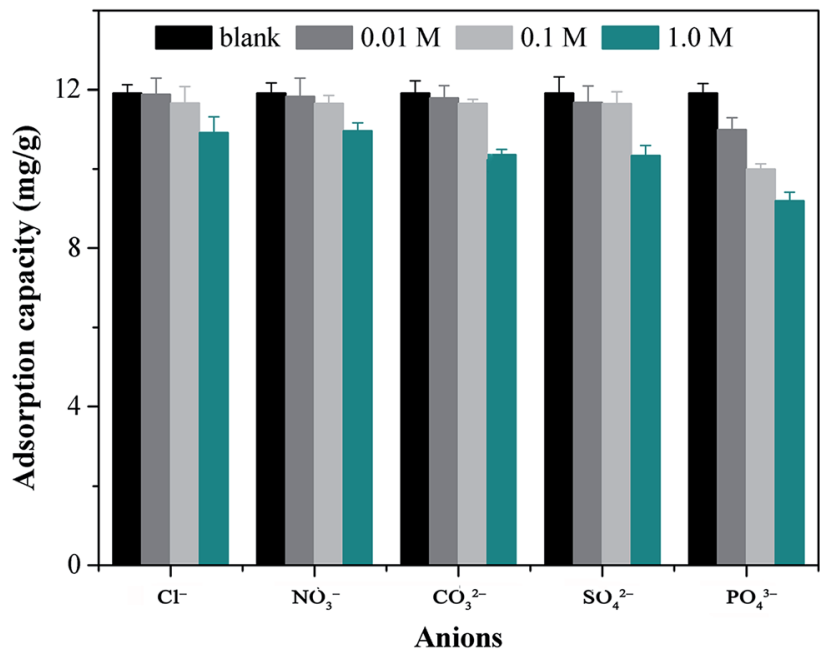

Fig. 5 Effect of various co-existing anions on As(v) adsorption for MCB.

state of MCB and decrease the availability of binding sites. ${ }^{36}$ On the other hand, it was observed that the presence of $\mathrm{CO}_{3}{ }^{2-}$ and $\mathrm{SO}_{4}{ }^{2-}$ had a greater impact on $\mathrm{As}(\mathrm{v})$ removal compared with the $\mathrm{Cl}^{-}$and $\mathrm{NO}_{3}{ }^{-}$, however, $\mathrm{PO}_{4}{ }^{3-}$ could cause the greatest decrease in $\mathrm{As}(\mathrm{v})$ adsorption, which might be due to the strong competition between the $\mathrm{PO}_{4}{ }^{3-}$ and $\mathrm{As}(\mathrm{v})$ for the binding sites of the adsorbent. Thus, it might occupy more adsorption sites compared to the other anions. In the practical application, some pretreatment before adsorption to reduce the concentration of various anions might be beneficial for contaminant removal.

\subsection{Effect of contact time and adsorption kinetics}

The effect of contact time on As(v) adsorption onto MCB is illustrated in Fig. 6a, and the inset shows the linear plot of pseudo-second-order. The adsorption process could be divided into two regions. In the first stage, the adsorption rate was very fast, and over $90 \%$ of the equilibrium adsorption capacity was achieved within $30 \mathrm{~min}$, which could be owing to the existence of abundant active sites on the surface of adsorbents. In the subsequent step, the process was slow, and the equilibrium was reached in about $3 \mathrm{~h}$. It might be attributed to the great decline of binding sites on adsorbents surface and the aggregation between particles. ${ }^{37}$ The kinetic of As(v) adsorption onto MCB was applied in order to understand the adsorption behaviors of MCB composite. The adsorption data of As(v) at different time intervals was simulated by pseudo-first-order and pseudosecond-order model. The equations are illustrated as follows:

Non-linear pseudo-first-order:

$$
q_{\mathrm{t}}=q_{\mathrm{e}, 1}\left(1-\mathrm{e}^{-k_{1} t}\right)
$$

Non-linear pseudo-second-order:

$$
q_{t}=\frac{q_{\mathrm{e}, 2}{ }^{2} k_{2} t}{1+q_{\mathrm{e}, 2} k_{2} t}
$$
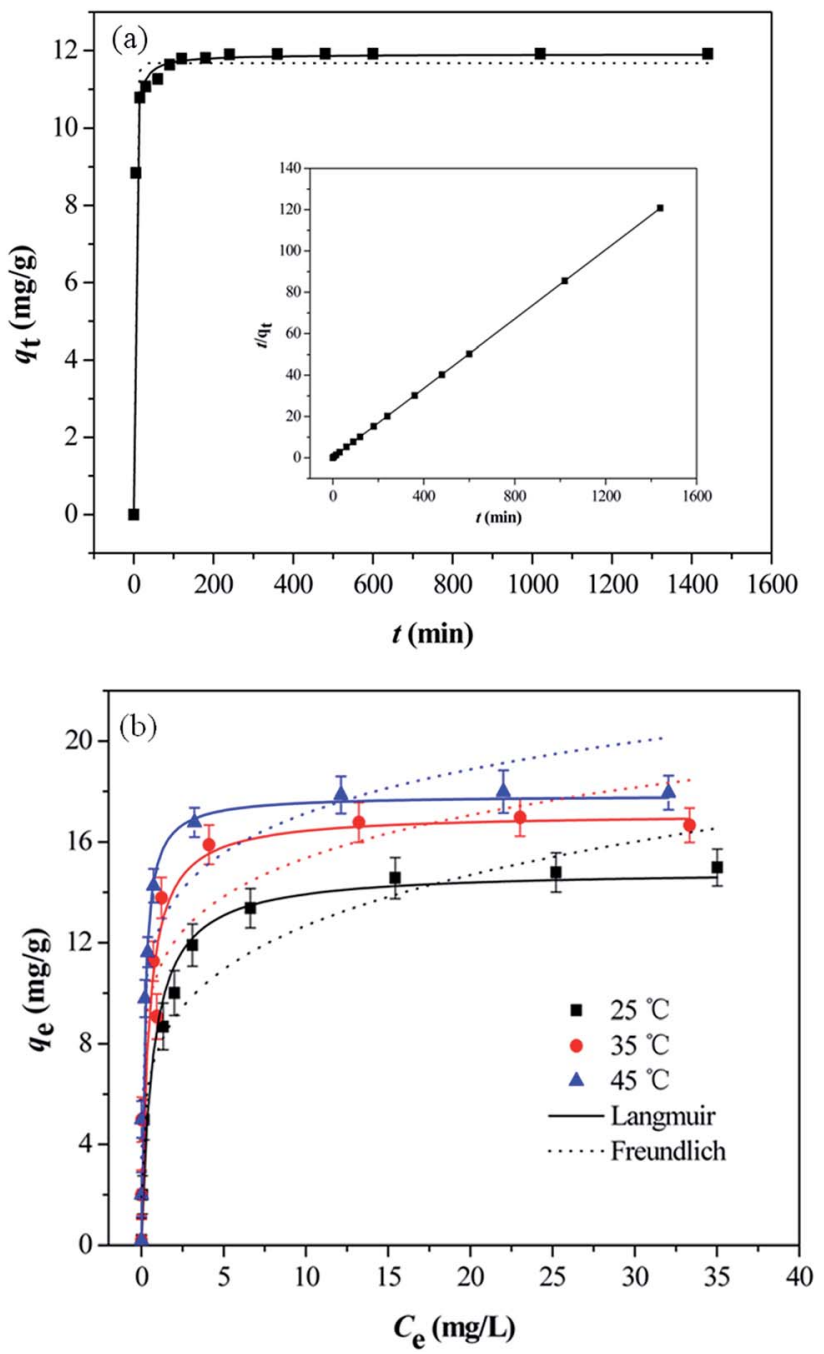

Fig. 6 (a) Pseudo-first-order (dot line) and pseudo-second-order (solid line) non-linear plots of adsorption kinetics for As(v) onto MCB. (b) Langmuir and Freundlich non-linear plots of isotherm for As(v) adsorption onto MCB at different temperatures.

Linear pseudo-second-order:

$$
\frac{t}{q_{t}}=\frac{1}{k_{2} q_{\mathrm{e}, 2}^{2}}+\frac{t}{q_{\mathrm{e}}}
$$

where $q_{t}\left(\mathrm{mg} \mathrm{g}^{-1}\right)$ is the mass of As(v) adsorbed per gram at time $t(\min ), q_{\mathrm{e}, 1}$ and $q_{\mathrm{e}, 2}\left(\mathrm{mg} \mathrm{g}^{-1}\right)$ are the adsorption capacity calculated by pseudo-first-order and pseudo-second-order model, respectively, $k_{1}\left(\mathrm{~min}^{-1}\right)$ and $k_{2}\left(\mathrm{~g} \mathrm{mg}^{-1} \mathrm{~min}^{-1}\right)$ are the adsorption rate constant of pseudo-first-order and pseudosecond-order model. After being fitted by these models, the calculated parameters are listed in Table 1 . It was obviously to find that the correlation coefficient $\left(R^{2}\right)$ of pseudo-second-order (0.999) was higher than the pseudo-first-order (0.988), and the calculated $q_{\mathrm{e}}$ represented a better agreement with the detected values in experiment. Therefore, the adsorption kinetics of As(v) onto MCB could be well-described by pseudo-second-order model, suggesting a chemisorption process might be involved in adsorption. 
Table 1 Kinetic parameters for adsorption of $A s(v)$ onto MCB

\begin{tabular}{llllllll}
\hline \multicolumn{2}{l}{ Pseudo-first-order model } & & & \multicolumn{3}{l}{ Pseudo-second-order model } \\
\cline { 5 - 7 }$k_{1}\left(\mathrm{~min}^{-1}\right)$ & $q_{\mathrm{e}}\left(\mathrm{mg} \mathrm{g}^{-1}\right)$ & $R^{2}$ & & $k_{2}\left(\mathrm{~g} \mathrm{mg}^{-1} \mathrm{~min}^{-1}\right)$ & $q_{\mathrm{e}}\left(\mathrm{mg} \mathrm{g}^{-1}\right)$ & $R^{2}$ & $q_{\mathrm{e}, \exp }\left(\mathrm{mg} \mathrm{g}^{-1}\right)$ \\
\hline 0.273 & 11.681 & 0.988 & 0.048 & 11.907 & 0.999
\end{tabular}

\subsection{Adsorption isotherm}

To describe the equilibrium established between adsorbed As(v) on the adsorbent and the remaining As(v) in the solution, two widespread-used isotherm models (Langmuir and Freundlich models) were applied to describe the equilibrium characteristics of the adsorption. The Langmuir adsorption model assumed that all the binding sites were equal and the adsorbent surface is homogeneous, while the Freundlich isotherm model was an empirical equation for explaining heterogeneous adsorption process. ${ }^{38}$ Both the two models were expressed as follows:

Langmuir:

$$
q_{\mathrm{e}}=\frac{q_{\max } K_{\mathrm{L}} C_{\mathrm{e}}}{1+K_{\mathrm{L}} C_{\mathrm{e}}}
$$

Freundlich:

$$
q_{\mathrm{e}}=K_{\mathrm{F}} C_{\mathrm{e}}^{1 / n}
$$

where $C_{\mathrm{e}}$ and $q_{\mathrm{e}}\left(\mathrm{mg} \mathrm{g}^{-1}\right)$ represent the equilibrium concentration and the adsorption capacity at equilibrium, respectively, $q_{\max }\left(\mathrm{mg} \mathrm{g}^{-1}\right)$ is the maximum adsorption capacity, $K_{\mathrm{L}}\left(\mathrm{L} \mathrm{mg}^{-1}\right)$ is the constant that related to free energy of adsorption; $K_{\mathrm{F}}$ is the Freundlich constant related to sorption capacity; $n$ is the empirical parameter varied with the degree of heterogeneity of adsorbing sites.

Fig. 6b showed As(v) sorption isotherms on the MCB at three different temperatures. The relative parameters calculated from the Langmuir and Freundlich isotherm models were listed in Table 2. As can be seen from Fig. 6b, the sorption isotherm maximum (17.876 $\mathrm{mg} \mathrm{g}^{-1}$ ) was at $45{ }^{\circ} \mathrm{C}$ and minimum $\left(14.928 \mathrm{mg} \mathrm{g}^{-1}\right)$ at $25{ }^{\circ} \mathrm{C}$. This result indicated that As(v) sorption on the MCB was promoted at higher temperature. According to the coefficient correlation $\left(R^{2}\right)$ obtained from Table 2, Langmuir isotherm had a better fitting model than the Freundlich isotherms model, suggesting that As(v) sorption on the MCB was a monolayer coverage. Additionally, $K_{\mathrm{L}}$ increased with the increasing of the temperature, which indicated that the adsorption of As(v) onto MCB was an endothermic process.
Another parameter $R_{\mathrm{L}}$, a dimensionless constant separation parameter, is given by the following equation:

$$
R_{\mathrm{L}}=\frac{1}{1+K_{\mathrm{L}} C_{0}}
$$

where $C_{0}$ is the highest initial concentration of $\mathrm{As}(\mathrm{v})\left(\mathrm{mg} \mathrm{L}^{-1}\right)$. This parameter indicates that the isotherm is unfavorable $\left(R_{\mathrm{L}}>\right.$ 1 ), favorable $\left(0<R_{\mathrm{L}}<1\right)$, linear $\left(R_{\mathrm{L}}=1\right)$, or irreversible $\left(R_{\mathrm{L}}=0\right){ }^{39}$ In this study, $R_{\mathrm{L}}$ values calculated between 0.003 and 0.015 , which proves that the adsorption is a favorable process. In comparison with other adsorbents at different solution $\mathrm{pH}$ (Table 3), the maximum As(v) sorption capacity of MCB was greater than many previous reported adsorbents. ${ }^{17,40-42}$

\subsection{Adsorption thermodynamic studies}

Thermodynamic parameters such as the Gibbs free energy change $\left(\Delta G^{\circ}\right)$, enthalpy change $\left(\Delta H^{\circ}\right)$, and entropy change $\left(\Delta S^{\circ}\right)$ were used to evaluate the feasibility and nature of adsorption reaction. They were determined by using the following equations:

$$
\begin{aligned}
& \Delta G^{\circ}=-R T \ln K^{\circ} \\
& \ln K^{\circ}=\frac{\Delta S^{\circ}}{R}-\frac{\Delta H^{\circ}}{R T}
\end{aligned}
$$

where $R\left(8.314 \mathrm{~J} \mathrm{~mol}^{-1} \mathrm{~K}^{-1}\right)$ is universal gas constant and $T(\mathrm{~K})$ is the solution temperature. $K^{\circ}$ is the adsorption equilibrium constant, which was calculated by plotting $\ln K_{\mathrm{d}}\left(K_{\mathrm{d}}=q_{\mathrm{e}} / C_{\mathrm{e}}\right)$ versus $C_{\mathrm{e}}$ and extrapolating $C_{\mathrm{e}}$ to zero.

\begin{tabular}{|c|c|c|c|c|c|c|}
\hline Temperature $\left({ }^{\circ} \mathrm{C}\right)$ & \multicolumn{3}{|l|}{ Langmuir } & \multicolumn{3}{|l|}{ Freundlich } \\
\hline 35 & 17.164 & 2.275 & 0.906 & 10.604 & 6.094 & 0.898 \\
\hline 45 & 17.876 & 5.805 & 0.945 & 11.992 & 6.676 & 0.900 \\
\hline
\end{tabular}

Table 3 Comparison of the maximum As(v) adsorption capacity with other adsorbents

\begin{tabular}{llll}
\hline Adsorbents & Solution pH & $\begin{array}{c}\text { Adsorption } \\
\text { capacity }\left(\mathrm{mg} \mathrm{g}^{-1}\right)\end{array}$ & References \\
\hline Charred dolomite & 7.2 & 2.157 & 40 \\
Iron-impregnated biochar & 5.8 & 2.160 & 17 \\
Activated bauxite & 3.5 & 6.900 & 41 \\
Activated alumina & 2.6 & 12.340 & 42 \\
Magnetic chitosan biochar & 5.0 & 17.876 & This study
\end{tabular}

Table 2 Langmuir and Freundlich isotherm parameters for adsorption of $A s(v)$ onto MCB 
Table 4 Thermodynamic parameters for As(v) onto MCB

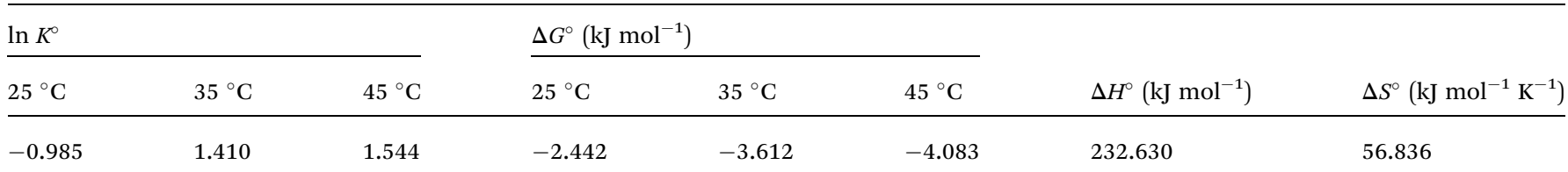

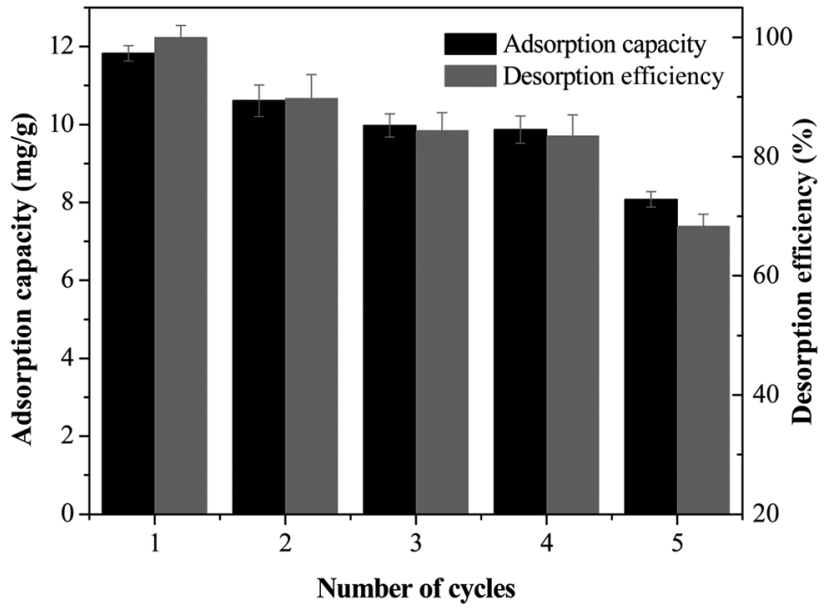

Fig. 7 Five consecutive adsorption-desorption cycles of MCB for As(v) removal.
Thermodynamic analysis was investigated at three different temperatures $\left(25,35\right.$, and $\left.45{ }^{\circ} \mathrm{C}\right)$. The calculated results are shown in Table 4 . The $\Delta H^{\circ}$ and $\Delta S^{\circ}$ values were found to be $232.630 \mathrm{~kJ} \mathrm{~mol}^{-1}$ and $56.836 \mathrm{~J} \mathrm{~mol}^{-1} \mathrm{~K}^{-1}$, respectively. The $\Delta G^{\circ}$ values were negative at the studied temperature, which was $-2.442 \mathrm{~kJ} \mathrm{~mol}^{-1},-3.612 \mathrm{~kJ} \mathrm{~mol}^{-1}$ and $-4.083 \mathrm{~kJ} \mathrm{~mol}^{-1}$, at 25, 35 , and $45{ }^{\circ} \mathrm{C}$, respectively. It was obvious that the $\Delta G^{\circ}$ values became more negative as the temperature increased, which indicated that the adsorption was spontaneity and more favorable at high temperature. The positive $\Delta H^{\circ}$ value implied that the adsorption reaction was endothermic, and it was the reason why the adsorption capacity of $\mathrm{As}(\mathrm{v})$ increased along with the increase of temperature. This was consistent with the isotherm analysis at different temperature. In addition, the positive $\Delta S^{\circ}$ indicated that the degrees of freedom increased at the solid-liquid interface during the adsorption process.
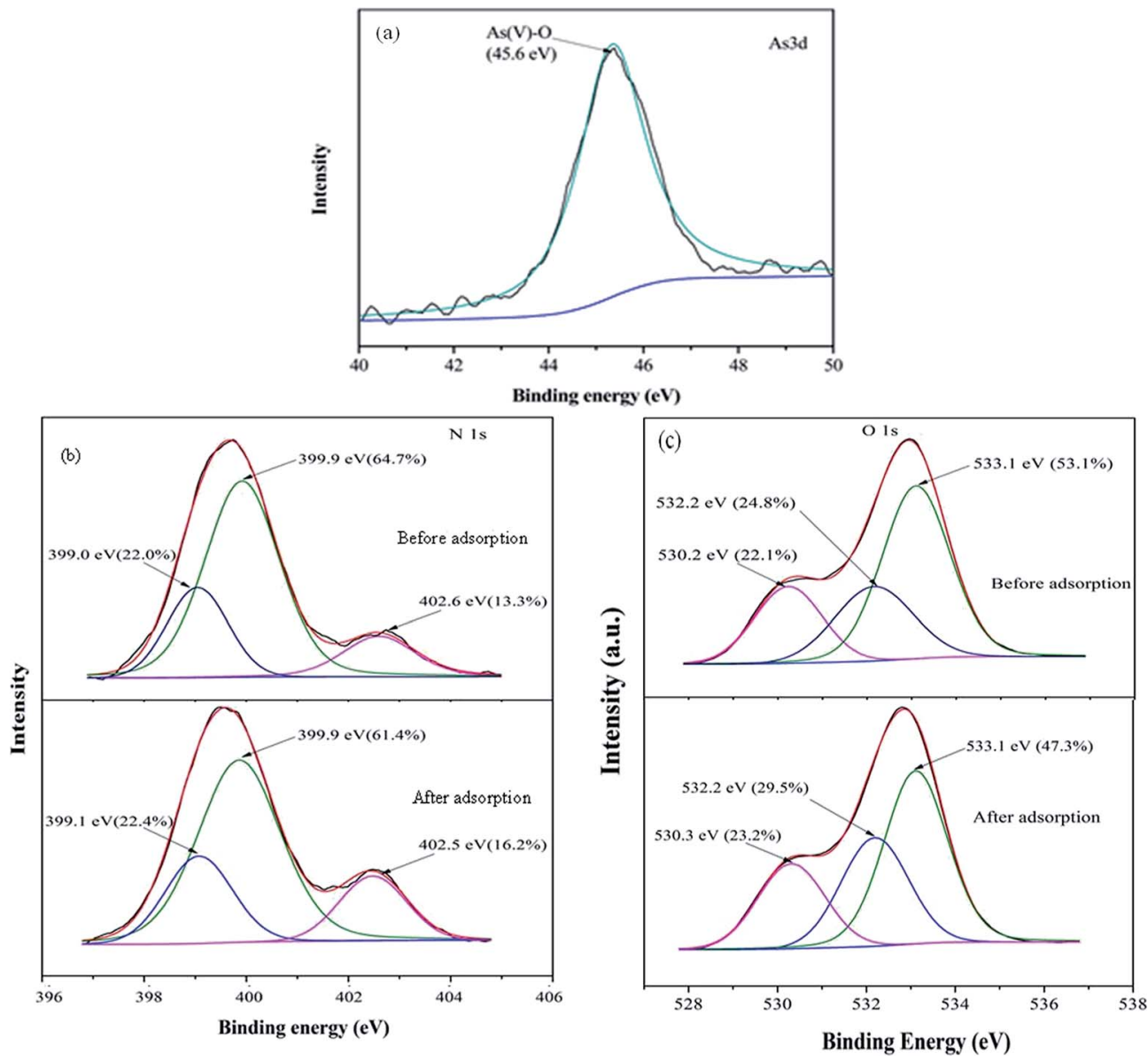

Fig. 8 The XPS high-resolution spectra of (a) As 3d, (b) N 1s and (c) O 1s. 


\subsection{Reusability of adsorbent}

The reversibility and desorption efficiency are important parameters to determine the reusability and economic feasibility. In this study, $1.0 \mathrm{~mol} \mathrm{~L}{ }^{-1} \mathrm{NaOH}$ solution was selected as a stripping reagent to study the reusability and desorption efficiency for 5 times, and the results are presented in Fig. 7. The MCB maintained $11.823 \mathrm{mg} \mathrm{g}^{-1}$ adsorption capacity for As(v) after one adsorption-desorption cycle. After 5 cycles of reuse, the regenerated MCB still retained about $8.078 \mathrm{mg} \mathrm{g}^{-1}$ uptake capacity for As(v), indicting a good reusability of adsorbent for As(v) removal. However, the decreasing of adsorption capacity could be assigned to the reduction of surface area and pore volume, and the relatively weak functional groups. ${ }^{34}$ The desorption efficiency was decreased slowly from $98 \%$ to $68 \%$, and it still presented a relatively high removal efficiency after 5 adsorption-desorption experiments.

\subsection{Adsorption mechanism}

To investigate the mechanism of As(v) removal, XPS analysis has been carried out and the wide XPS spectra of the MCB composite after As(v) adsorption was given in Fig. 3a. After As(v) adsorption, typical As 3d XPS peak appeared. In Fig. 8a, which was assigned to the $\mathrm{As}(\mathrm{v})-\mathrm{O},{ }^{43}$ so it can be demonstrated MCB could be used to eliminate $\mathrm{As}(\mathrm{v})$ from aqueous solution. Furthermore, Fig. 8b reflected the N 1s XPS spectra of MCB before and after As(v) adsorption. The $\mathrm{N}$ 1s spectrum of MCB could be deconvoluted into three peak component with binding energies (BEs) at 399.0, 399.9, and $402.5 \mathrm{eV}$, which were consistent with the amine $\left(-\mathrm{NH}_{2}\right)$, amide $(-\mathrm{NH}-)$, and protonated amine $\left(\mathrm{N}^{+}\right)$, respectively. ${ }^{\mathbf{4 4}}$ After As(v) adsorption, the molar ratio of $\mathrm{N}^{+}$increased significantly from $13.3 \%$ to $16.2 \%$, the -NH- decreased from $64.7 \%$ to $61.4 \%$, and the $-\mathrm{NH}_{2}$ had little changes, which indicated that the $\mathrm{N}^{+}$might play a key role in As(v) removal owing to the presence of $\mathrm{N}^{+}$could absorb negatively charged $\mathrm{H}_{2} \mathrm{AsO}_{4}{ }^{-}$or $\mathrm{HAsO}_{4}{ }^{2-}$ through electrostatic attraction and it was explained that the removal efficiency of As(v) was significantly improved after grafting chitosan on biochar. The O 1s XPS spectrum of MCB composite before and after adsorption is shown in Fig. 8c. It was noted that there were three peaks centered at 530.2, 532.2 and $533.1 \mathrm{eV}$ in MCB spectra, which was assigned to $\mathrm{Fe}-\mathrm{O}(22.1 \%),-\mathrm{OH}(24.8 \%)$ and $\mathrm{O}-\mathrm{C}-\mathrm{O}(53.1 \%) .{ }^{45}$ However, after As(v) adsorption, the molar ratio of the surface $\mathrm{Fe}-\mathrm{O}$ groups increased to $23.2 \%$, which might be due to the formation of $\mathrm{Fe}-\mathrm{O}-\mathrm{As}$ groups on the adsorbent surface after As(v) adsorption, and it also explains why the magnetic fluid modification greatly enhanced CB's sorption ability to As(v). Furthermore, the peaks at $532.2 \mathrm{eV}$ due to $-\mathrm{OH}$ group, and the molar ratio increased from $24.8 \%$ to $29.5 \%$, which might be owing to the reaction between - $\mathrm{OH}$ from MCB and As(v) via electrostatic attraction, and the results were consistent with the $\mathrm{pH}$ analysis.

\section{Conclusion}

The magnetic chitosan/biochar composite (MCB) was prepared successfully as a low-cost adsorbent to remove $\mathrm{As}(\mathrm{v})$ from aqueous solution. The adsorption experiment indicated that there was an obvious enhanced adsorption capacity of As(v) after modification. The experimental data was better fitted by the pseudo-second-order and Langmuir model, and the maximum adsorption capacity $\left(17.876 \mathrm{mg} \mathrm{g}^{-1}\right)$ was obtained at $\mathrm{pH} 5,45^{\circ} \mathrm{C}$. The sorption reaction was an endothermic and spontaneous process. Based on the experiments, the interaction between As(v) and MCB might include electrostatic attraction and the increased adsorption sites that iron provided.

\section{Acknowledgements}

This work was supported by the National Natural Science Foundation of China (Grant no. 51609268, 41271332, 51521006 and 51478470).

\section{References}

1 I. Andjelkovic, D. N. Tran, S. Kabiri, S. Azari, M. Markovic and D. Losic, ACS Appl. Mater. Interfaces, 2015, 7, 9758-9766.

2 C. H. Liu, Y. H. Chuang, T. Y. Chen, Y. Tian, H. Li, M. K. Wang and W. Zhang, Environ. Sci. Technol., 2015, 49, 7726-7734.

3 C.-W. Huang, C.-C. Wei and V. H.-C. Liao, Chemosphere, 2015, 141, 44-49.

4 Q. Sun, Y. Song, S. Liu, F. Wang, L. Zhang, S. Xi and G. Sun, Atmos. Environ., 2015, 118, 1-6.

5 X. Liu, W. Zhang, Y. Hu and H. Cheng, Microchem. J., 2013, 108, 38-45.

6 S. S. Nielsen, L. Petersen, P. Kjeldsen and R. Jakobsen, Chemosphere, 2011, 84, 383-389.

7 H. Guo, D. Wen, Z. Liu, Y. Jia and Q. Guo, Appl. Geochem., 2014, 41, 196-217.

8 J. Tong, H. Guo and C. Wei, Sci. Total Environ., 2014, 496, 479-487.

9 H. Guo, Y. Ren, Q. Liu, K. Zhao and Y. Li, Environ. Sci. Technol., 2013, 47, 1009-1016.

10 P. Smedley and D. Kinniburgh, Appl. Geochem., 2002, 17, 517-568.

11 P. Chutia, S. Kato, T. Kojima and S. Satokawa, J. Hazard. Mater., 2009, 162, 440-447.

12 O. Coronell, B. Mi, B. J. Mariñas and D. G. Cahill, Environ. Sci. Technol., 2012, 47, 420-428.

13 A. Dominguez-Ramos, K. Chavan, V. n. García, G. Jimeno, J. Albo, K. V. Marathe, G. D. Yadav and A. Irabien, Ind. Eng. Chem. Res., 2014, 53, 18920-18927.

14 A. Molinari, L. Guadagnini, M. Marcaccio, S. Straface, X. Sanchez-Vila and A. Guadagnini, Sci. Total Environ., 2013, 444, 231-240.

15 S. Bordoloi, S. K. Nath, S. Gogoi and R. K. Dutta, J. Hazard. Mater., 2013, 260, 618-626.

16 I. Ali, Chem. Rev., 2012, 112, 5073-5091.

17 X. Hu, Z. Ding, A. R. Zimmerman, S. Wang and B. Gao, Water Res., 2015, 68, 206-226.

18 L. Lou, L. Yao, G. Cheng, L. Wang, Y. He and B. Hu, PLoS One, 2015, 10, e0137467. 
19 X. Tan, Y. Liu, G. Zeng, X. Wang, X. Hu, Y. Gu and Z. Yang, Chemosphere, 2015, 125, 70-85.

20 L. Beesley and M. Marmiroli, Environ. Pollut., 2011, 159, 474480.

21 Y. Zhou, B. Gao, A. R. Zimmerman, J. Fang, Y. Sun and X. Cao, Chem. Eng. J., 2013, 231, 512-518.

22 B. Huang, Y. Liu, B. Li, G. Zeng, X. Hu, B. Zheng, T. Li, L. Jiang, X. Tan and L. Zhou, RSC Adv., 2015, 5, 106339106349.

23 A. Adamczuk and D. Kołodyńska, Chem. Eng. J., 2015, 274, 200-212.

24 Y.-F. Lin, J.-L. Chen, C.-Y. Xu and T.-W. Chung, Chem. Eng. J., 2014, 250, 409-415.

25 L. Fan, C. Luo, X. Li, F. Lu, H. Qiu and M. Sun, J. Hazard. Mater., 2012, 215-216, 272-279.

26 X. J. Hu, J. S. Wang, Y. G. Liu, X. Li, G. M. Zeng, Z. L. Bao, X. X. Zeng, A. W. Chen and F. Long, J. Hazard. Mater., 2011, 185, 306-314.

27 C. Cao, L. Xiao, C. Chen, X. Shi, Q. Cao and L. Gao, Powder Technol., 2014, 260, 90-97.

28 H. Deng, X. Li, Q. Peng, X. Wang, J. Chen and Y. Li, Angew. Chem., 2005, 117, 2842-2845.

29 F.-y. Guo, Y.-g. Liu, H. Wang, G.-m. Zeng, X.-j. Hu, B.-h. Zheng, T.-t. Li, X.-f. Tan, S.-f. Wang and M.-m. Zhang, RSC Adv., 2015, 5, 45384-45392.

30 B. Chen, Z. Chen and S. Lv, Bioresour. Technol., 2011, 102, 716-723.
31 M.-m. Zhang, Y.-g. Liu, T.-t. Li, W.-h. Xu, B.-h. Zheng, X.-f. Tan, H. Wang, Y.-m. Guo, F.-y. Guo and S.-f. Wang, RSC Adv., 2015, 5, 46955-46964.

32 K. Elwakeel, Int. J. Environ. Sci. Technol., 2014, 11, 1051-1062.

33 M. X. Loukidou, K. A. Matis, A. I. Zouboulis and M. Liakopoulou-Kyriakidou, Water Res., 2003, 37, 4544-4552.

34 C. Gan, Y. Liu, X. Tan, S. Wang, G. Zeng, B. Zheng, T. Li, Z. Jiang and W. Liu, RSC Adv., 2015, 5, 35107-35115.

35 Y.-F. Pan, C. T. Chiou and T.-F. Lin, Environ. Sci. Pollut. Res., 2010, 17, 1401-1410.

36 H. Wang, X. Yuan, Y. Wu, H. Huang, G. Zeng, Y. Liu, X. Wang, N. Lin and Y. Qi, Appl. Surf. Sci., 2013, 279, 432-440.

37 L. Fan, C. Luo, M. Sun, X. Li and H. Qiu, Colloids Surf., B, 2013, 103, 523-529.

38 E. Agrafioti, D. Kalderis and E. Diamadopoulos, J. Environ. Manage., 2014, 133, 309-314.

39 Z. Wu, X. Yuan, H. Zhong, H. Wang, G. Zeng, X. Chen, H. Wang, L. Zhang and J. Shao, Sci. Rep., 2016, 6, 25638.

40 Y. Salameh, A. B. Albadarin, S. Allen, G. Walker and M. N. M. Ahmad, Chem. Eng. J., 2015, 259, 663-671.

41 H. S. Altundoğan, S. Altundoğan, F. Tümen and M. Bildik, Waste Manag., 2002, 22, 357-363.

42 T.-F. Lin and J.-K. Wu, Water Res., 2001, 35, 2049-2057.

43 Y.-X. Zhang and Y. Jia, Appl. Surf. Sci., 2014, 290, 102-106.

44 X. Yang, Y. Tu, L. Li, S. Shang and X.-m. Tao, ACS Appl. Mater. Interfaces, 2010, 2, 1707-1713.

45 N. A. Travlou, G. Z. Kyzas, N. K. Lazaridis and E. A. Deliyanni, Langmuir, 2013, 29, 1657-1668. 